\title{
Exploração de necessidades socio- educativas e análise de modelos formativos de educação ambiental com caráter experimental
}

\section{Exploration of socio-educational demands and experimental analysis of formative models in environmental education}

\author{
Vilma Maria Marcassa Barra*
}

\begin{abstract}
RESUMO
Neste artigo apresentamos uma síntese de tese doutoral defendida há cinco anos, mas de plena validade referencial, quanto a conteúdo e método. A pesquisa, caracterizada como um projeto de intervenção socioeducativa, foi desenvolvida em uma escola da Rede de Ensino Municipal de PinhaisPR, na região metropolitana de Curitiba. Foi implementado e testado um enfoque interdisciplinar de Educação Ambiental no sistema escolar a partir de um modelo multidisciplinar (Método de Infusão), tendo como diretriz a ambientalização do currículo escolar. O trabalho teve três etapas: o marco teórico - análise conceitual da EA; EA: necessidade, origem e desenvolvimento; a análise do contexto - Paraná: marco contextual; o município de Pinhais: estudo contextual; o estudo empírico - análise de necessidades; o projeto de intervenção socioeducativa; análise e interpretação dos dados; conclusões e sugestões. Nesta síntese, no entanto, nos limitaremos a apresentar os dados relativos ao estudo empírico.

Palavras-chave: Educação Ambiental; ambientalização do currículo; método de infusão.
\end{abstract}

* Doutora em Filosofia e Ciências da Educação pela Universidade de Santiago de Compostela, Professora do Departamento de Teoria e Prática de Ensino, Setor Educação/UFPR; Colaboradora do Núcleo Interdisciplinar de Meio Ambiente e Desenvolvimento (NIMAD)/UFPR. E-mail: vilmabar@ufpr.br 
BARRA, V. M. Exploração de necessidades socioeducativas...

\begin{abstract}
The present text renders a synthesis from a Doctoral Thesis academically appraised five years ago, nevertheless retaining referential value both as to content and method. The research was developed as a socioeducative intervening project within one school of the Municipal School Net of Pinhais-PR, in the Metropolitan Region of Curitiba. It was implemented and tested an interdisciplinary concept of Environmental Education, departing from a multidisciplinary schooling model (Infusion Method) and directed to an environmentalization of the school curriculum. The project had three phases: theoretical referral - conceptual analysis of EA, including its urgency, roots and development; contextual analysis - the cases of Paraná State, as delimiting context, as of the Pinhais Municipality, as study context; and empirical research - needs assessment, developing of the intervening project, data analysis and interpretation, conclusions and suggestions. That text restricts itself to presenting data from the empirical research of the global study conducted as a thesis.

Key-words: Environmental Education; school curriculum environmentalization; infusion method.
\end{abstract}

\title{
Introdução
}

Educação Ambiental: processo educativo mediante o qual os indivíduos adquirem conhecimentos, desenvolvem valores, habilidades e comportamentos que lhes permitem tomar decisões responsáveis no que se refere à sua interação no meio ambiente, visando a manutenção da qualidade ambiental e o desenvolvimento de sociedades sustentáveis. A concordância com esse conceito implica algumas considerações: 1) a educação ambiental (EA) é entendida como um processo educativo dotado de identidade e fundamentação teórica; 2) o meio ambiente deixa de ser apenas uma fonte de conhecimentos, um recurso educativo para tornar-se no componente essencial e, conseqüentemente prioritário, do planejamento escolar; 3) o objetivo dos processos educativos desloca-se da prioridade na formação e aperfeiçoamento do homem como sujeito (visão antropocêntrica), para a formação e aperfeiçoamento do homem com vistas à melhoria do ambiente (visão biocêntrica). A questão central passa a ser, não mais o destino dos homens, mas o destino do Planeta, numa visão solidária em que o homem e os demais componentes da natureza agem como uma totalidade na busca permanente da preservação da vida; 4) uma nova ética é estabelecida 
no que se refere às relações entre o homem e os demais componentes da natureza: esses passam a ter valor intrínseco; 5) a EA, com base na nova ética, deverá promover, nos alunos, o desenvolvimento de valores que os levem à ação, à prática de novos e positivos comportamentos ambientais resultantes da tomada de decisões responsáveis. Em suma, os alunos devem adquirir uma atitude de responsabilidade para com o meio ambiente.

Nesse contexto uma questão se impõe: como operacionalizar tal processo educativo? A resposta a tal indagação pode ser encontrada nas metas e objetivos da EA estabelecidos no Seminário Internacional de Educação Ambiental de Belgrado (1975), ratificados na Conferência Intergovernamental de Educação Ambiental realizada em Tbilisi (1977): conseguir que a população mundial tenha consciência do meio ambiente, se interesse por ele e pelos seus problemas e adquira os conhecimentos, atitudes, habilidades, motivação e desejo necessários para trabalhar individual e coletivamente na busca de soluções para os problemas ambientais atuais e na prevenção dos futuros. Para o alcance de tais metas, a EA deverá priorizar os objetivos que concorram para a formação de cidadãos ambientalmente responsáveis, cidadãos capazes de se sensibilizar e valorizar o meio ambiente a ponto de buscarem conhecimentos que possibilitem a formação de valores e atitudes de empatia para com o entorno que os levem a participar ativamente não só na resolução dos problemas, como também na tomada de decisões a respeito das questões ambientais.

No sistema escolar, especificamente, para que a EA adquira a eficácia e a eficiência desejadas deverá ocorrer a superação de obstáculos tais como:

- a ênfase no estudo do meio que busca instruir e formar os alunos; o que se preconiza é a educação para o meio, proposta pela pedagogia ambiental, que visa, acima de tudo, a ensinar os alunos a usar judiciosamente os recursos do meio;

- a valoração excessiva de métodos e estratégias de ensino baseados na transmissão, pelo professor, de informações e conceitos pré-estabelecidos, nem sempre adequados à realidade do aluno - métodos e estratégias que, ademais, implicam sempre uma postura passiva dos alunos;

- a ênfase na aquisição de informações em detrimento do desenvolvimento de habilidades de investigação, avaliação e ação;

- a centralização da discussão e estudos nos problemas ambientais existentes, fato que favorece a colocação da questão relativa à prevenção dos problemas em segundo plano;

- a não inclusão da variável sensibilidade ambiental, definida como uma perspectiva de empatia para com o meio ambiente, na prática escolar;

- a ausência da prática da clarificação de valores que determinam as atitudes e ações no ambiente;

- a fragmentação do conhecimento, fato que impossibilita uma visão 
BARRA, V. M. Exploração de necessidades socioeducativas...

abrangente das questões ambientais, por sua vez facilitada por um enfoque interdisciplinar;

- a concepção tradicional de escola que se caracteriza pelo fato de os processos de ensino se centrarem na sala de aula, dificultando a ocorrência de uma abertura para o meio.

Torna-se impossível o estabelecimento de um modelo universal para a integração da educação ambiental no currículo escolar. Uma diretriz, porém, parece se impor: a necessidade de "se ambientalizar" o currículo, algo mais radical e inovador que afeta o sistema globalmente. Tal necessidade decorre do fato de que a educação, como prática social, ocorre sempre em um ambiente específico que se torna uma variável determinante e inseparável dos processos educacionais. Esse fato é mais evidente na EA de vez que esta ocorre no meio, sobre o meio e para o meio, na busca da solução de problemas ambientais (CARIDE, 1991, p. 43). Ambientalizar o currículo significa, pois, ajustá-lo de forma coerente com os princípios éticos, conceituais e metodológicos característicos da educação ambiental (Novo, 1995, p. 207). O meio ambiente torna-se, então, um componente fundamental do processo educativo. Isso posto, é necessário um novo entendimento do que seja meio ambiente. Um entendimento que ultrapasse a concepção de algo que existe e com o qual nos relacionamos e passe a significar algo que condiciona o desenvolvimento pessoal e coletivo. Considerando-se, dessa forma, que na EA o que importa é de que modo o ambiente pode se tornar um componente fundamental no processo de desenvolvimento dos indivíduos, no que se refere às suas relações com seus semelhantes e com os demais elementos da natureza, é válido o conceito estabelecido por Zabalza (1991, p. 245):

ambiente é todo o conjunto de elementos de diversas índoles e natureza (do geofísico ao cultural, do atual ao histórico, do inanimado ao espiritual) que interagem, criando um espaço específico no qual os homens constroem (e são construídos), a dinâmica de nossa existência.

O conceito abrange quatro espaços: o social, o território, a comunidade e os espaços concretos, cada qual com seus aspectos e características próprias e com influência no processo educativo. De acordo com Zabalza (1991, p. 258), o significado e o sentido da escola, a partir de uma perspectiva centrada no território como unidade de referência, se amplia significativamente ao incorporar 
três aspectos fundamentais: o sistema formativo territorial, o território como fonte de recursos e a escola como recurso do território, permanentemente disponível para o desenvolvimento cultural do próprio território. A abertura para o território significa que a escola considera o sistema formativo territorial e os modos como ocorre a sua relação com ele. Significa, ainda, que o ambiente e dentro dele o território -, não é somente algo que se estuda e se aprende a amar, mas também algo que se usa de maneira intensa para o desenvolvimento da aprendizagem. Segundo tal perspectiva, a escola torna-se um recurso para o desenvolvimento dos alunos e também da comunidade, desde que atue em estreita relação de complementaridade com os demais recursos oferecidos pelo território. Uma escola aberta ao território apresentará, necessariamente, um currículo comprometido com o ambiente, com previsão de atividades centradas no ambiente, desenvolvidas de forma interdisciplinar, orientadas à integração e à totalidade, com a utilização de recursos do território, sendo este, inclusive, fonte de conteúdos, coerentemente com as metas e objetivos da EA.

O desenvolvimento de um projeto de intervenção socioeducativa de EA em nível escolar, que incorpore as idéias e conceitos aqui descritos, torna-se imperativo quando envolve um determinado território, importante pela sua localização, características e inter-relações com os territórios vizinhos. Esse é o caso do município de Pinhais, no Estado do Paraná, por abrigar os mananciais de água que abastecem 78\% da Região Metropolitana de Curitiba e constituir-se em reduto dos pinheirais remanescentes da Floresta de Araucária.

Nesse contexto, situa-se o problema que suscitou a implementação do projeto: é possível desenvolver, de forma sistematizada, no sistema escolar, um projeto de intervenção socioeducativa de EA, que ambientalize o currículo e baseie-se em princípios metodológicos que possibilitem o alcance de suas metas e objetivos?

\section{Análise de necessidades}

Tendo em vista a implementação do projeto formativo, tornou-se necessária a realização de uma análise de necessidades, com o objetivo de coletar e analisar os dados visando a uma adequada decisão a respeito da amplitude do programa pretendido, seus objetivos, planejamento, desenvolvimento e avaliação. As ações, para tanto, basearam-se no modelo denominado ANISE (Análise de Necessidades de Intervención Sócio-educativa), proposto por Pérez-Campanero (1991), constituído por três fases: reconhecimento, diagnóstico 
BARRA, V. M. Exploração de necessidades socioeducativas...

e tomada de decisões. Cabe destacar que o processo de avaliação de necessidades constitui-se num tipo de avaliação formativa que enfatiza a descrição de uma comunidade e os processos de "feedback" necessários às propostas e ao desenvolvimento do programa educativo. É o ponto de partida do processo. Nesse sentido é válido o emprego de técnicas descritivas, que possibilitam a obtenção de informações mais amplas e qualitativamente valoráveis, isto é, que focalizam os valores, atitudes, interesses etc., das pessoas, no que se refere às questões ambientais.

\section{Fase de reconhecimento}

Nessa etapa buscou-se coletar os múltiplos dados que possibilitaram a realização da análise da comunidade, aqui entendida como o conjunto de indivíduos que vivem no local onde a pesquisa foi realizada, local onde se originam as raízes do seu processo de adaptação/desadaptação social (PÉREZCAMPANERo, 1991, p. 48). Com o objetivo de aprofundar a análise da comunidade foram selecionados onze moradores do município para que, em entrevistas, apresentassem suas percepções a respeito de Pinhais. Os entrevistados foram selecionados a partir dos critérios: tempo de moradia ou de atuação no município, participação em órgãos da administração relacionados ao estudo em questão e possibilidade de ação como formadores de opinião, em função de suas atividades profissionais. Optou-se por uma modalidade de entrevista qualitativa que combina o enfoque estandardizado aberto com aquele que prevê a elaboração prévia de roteiro (PATTON, 1989, p. 194-263). Ainda com o intuito de aprofundar a análise da comunidade foram realizadas as seguintes ações: a) entrevistas com pais de alunos de três escolas municipais, segundo a técnica de grupo central (PÉREZ-CAMPANERo, 1991, p. 83-90); b) aplicação a oitenta e cinco professoras em atuação nas $4^{\text {as }}$. séries do ensino fundamental e dezoito diretoras de escolas municipais, de instrumento composto de duas partes: escala de atitudes do tipo Likert e um questionário composto de três questões abertas: conceito de meio ambiente e de EA, relação dos problemas ambientais existentes em Pinhais considerados graves e a justificativa para tal qualificação; c) aplicação de questionário a trinta professoras de ciências das $4^{\text {as }}$. séries, em atuação em escolas do município; d) aplicação a setenta e oito alunos de $4^{\mathrm{a}}$. série de três escolas municipais de instrumento composto de duas 
partes: parte A: constituída de onze questões com três alternativas cada; as alternativas foram elaboradas a partir do The Environmental Concern Inventory (KELNNER, 1971), cujo objetivo é ajudar o professor a identificar tipos de problemas ou preocupações ambientais a respeito dos quais o aluno não tenha uma clara compreensão; as questões versavam sobre hábitos de higiene dos alunos, dos seus conhecimentos a respeito do que é certo ou errado em relação a esses hábitos, sobre sua percepção acerca das características ambientais dos bairros onde residem (as reais e as desejadas) e sobre os problemas ambientais dos grandes centros urbanos; parte B: desenhos elaborados pelos alunos com o objetivo de retratar o lugar onde moram - desenho, aqui, significando o trabalho gráfico da criança e que não é resultado de uma cópia, mas da construção e da interpretação do objeto pelo sujeito (PILLAR, 1996, p. 35).

Buscando informações adicionais a respeito das necessidades dos alunos, via sua percepção do local onde moram, solicitou-se que estes complementassem as suas informações citando aquilo que, na sua opinião, ali estaria faltando; e observação, pela pesquisadora, durante uma semana, dos comportamentos de alunos de quatro escolas municipais, visando a complementar e ampliar os dados obtidos anteriormente. Para tanto, foi elaborada uma escala de valoração estimativa, buscando-se assegurar a observância de requisitos técnicos que, segundo Zabalza (1993, p. 251), contribuem para a validade da observação: sistematização, objetividade, contextualização e confiabilidade. Compunham a escala as descrições de trinta e um comportamentos passíveis de serem apresentados pelos alunos, referentes aos seguintes aspectos: a atitude de zelo e interesse pela escola enquanto edifício, pelo seu entorno, pelos recursos didáticos existentes e disponíveis e pelos seus próprios pertences; a atitudes de preservação de recursos naturais; a atitudes de socialização; a atitudes de proximidade psicológica entre professoras e alunos; ao cumprimento de normas; indicadores de atitudes de interesse e zelo por animais e vegetais. É importante ressaltar que os dados coletados na observação foram complementados com o auxílio de outras fontes: professoras e funcionárias das escolas, alunos e moradores das proximidades das escolas.

\section{Fase de diagnóstico: do confronto entre a situação atual e a desejável à definição dos problemas}


BARRA, V. M. Exploração de necessidades socioeducativas...

\section{Identificação da situação atual}

Nessa etapa, considerada a central do modelo ANISE, buscou-se caracterizar - a partir da análise dos dados coletados - o estado atual do ensino da EA nas escolas municipais: sua adequação à clientela, aos anseios dos pais e moradores do município, aos problemas ambientais existentes na região, aos objetivos estabelecidos pela Secretaria Municipal de Educação, ao currículo das escolas, à competência das professoras para o seu ensino, à adequação e eficiência das atividades desenvolvidas e à ocorrência de interdisciplinaridade.

As respostas dos entrevistados e as apresentadas pelas professoras ao questionário foram analisadas segundo metodologia preconizada por Bardin (1977), denominada de Análise de conteúdo, que se desenvolve em três etapas básicas: pré-análise, exploração do material e tratamento dos resultados, ingerência e interpretação.

A análise das respostas das professoras à escala de atitudes (Likert), pelo número de variáveis e a natureza multivariada das questões, exigiu estudos mais complexos visando à melhor interpretação e análise dos dados. Utilizouse, então, a técnica de Análise fatorial, que permitiu estruturar e simplificar os dados, conservando o máximo de informação expressa pelas variáveis originais. No processo estatístico dessa análise, o número de variáveis ou categorias é reduzido a um número menor de variáveis hipotéticas, denominadas de fatores comuns, os quais possibilitam uma melhor compreensão dos dados. Quanto aos desenhos elaborados pelos alunos, realizou-se uma análise de conteúdos em que os elementos do meio ambiente representados foram agrupados em quatro categorias finais: biológicos, geofísicos, materiais resultantes da ação adequada do homem (escolas, parques etc.) e materiais resultantes da ação inadequada do homem (poluição, barulho etc.).

A partir da análise dos dados coletados, puderam-se estabelecer as seguintes conclusões, aqui apresentadas resumidamente: 1) os entrevistados demonstram uma preocupação não apenas com o embelezamento da cidade mas, acima de tudo, com o saneamento básico; com uma boa rede escolar e um serviço de saúde decente, considerando a inexistência de saneamento o principal problema ambiental do município. 2) Os mesmos problemas foram apontados pela professoras de $4^{\text {a }}$. série; contudo, quando se analisam as justificativas por elas apresentadas a respeito da gravidade desses problemas e o seu conceito de meio ambiente, verifica-se que a maioria possui uma visão tradicional, antropocêntrica, segundo a qual o homem é considerado como o centro de tudo e todas as demais coisas existem em função dele; assim, a maioria das professoras, considerando-se os seus conceitos e valores, demonstra uma preocupação com a qualidade de vida prioritariamente relacionada com a saúde humana, tendo como princípio básico o bem estar dos indivíduos. Não ficou evidente, nas suas respostas, uma 
preocupação no que diz respeito à formação, pelos alunos, de crenças positivas, valores e atitudes em relação ao meio ambiente, que constituiriam a base de seu comportamento ético responsável. 3) No que se refere ao conceito de EA, pôdese perceber que os sujeitos da pesquisa apresentam opiniões heterogêneas nem sempre bem definidas, que refletem variados posicionamentos que vão desde a visão conservacionista do meio ambiente (entendido como o espaço físico onde habitamos), até aquela que preconiza o desenvolvimento de valores positivos que orientariam os indivíduos a apresentar condutas social e ambientalmente corretas, visando à melhoria da qualidade de vida. 4) Uma análise específica do posicionamento das professoras revelou a inter-relação entre o seu conceito de meio ambiente e o de EA, sendo esse confundido com os seus objetivos. Dessa forma, para a maioria delas, a EA está direcionada primordialmente à preservação, cuidados, respeito e uso adequado do meio ambiente (físico) por ser esse um recurso necessário ao desenvolvimento do homem e não um bem em si, numa visão tradicional que nega a união homem-natureza e enfatiza os aspectos relacionados ao meio físico em detrimento da questão da preparação dos indivíduos (educação) para que esses sejam capazes de decidir sobre o futuro de um planeta do qual eles são parte e não unicamente beneficiários. 5) Quanto à importância da escola na EA, observou-se uma unanimidade de opiniões entre pais de alunos, professoras e pessoas da comunidade, mesmo que as justificativas apresentadas fossem de teores diversificados. Ressalta-se que, para os pais e para a maioria dos representantes da comunidade, a escola - para atender as exigências de uma EA voltada ao desenvolvimento de valores e atitudes ambientalmente corretas - deverá passar por modificações do currículo escolar e que incluam a qualificação das professoras. Nesse sentido, nota-se preocupação com um ensino que, acima de tudo, enfatize a formação de valores, atitudes e comportamentos fundamentados em um novo paradigma surgido da revisão de antigos valores que têm norteado nossas condutas até o presente momento. 6) Em relação aos conteúdos desenvolvidos nas escolas, pôde-se concluir que, apesar do predomínio daqueles diretamente relacionados às ciências físicas e biológicas, houve uma preocupação com a inclusão de tópicos mais abrangentes relacionados a fatores sociais, econômicos e políticos, mesmo que não contemplem a totalidade dos problemas existentes no município. Não se pode, no entanto, deixar de reconhecer o predomínio de assuntos relativos à conservação e proteção do meio físico. 7) No que se refere à integração da EA no currículo escolar, verifica-se uma aparente dicotomia: enquanto a maioria das professoras concorda que a EA pode e deve ser ensinada na escola em todas as oportunidades, não só pela relevância dos seus objetivos, mas também pela multiplicidade dos fatores envolvidos, na prática escolar as atividades de EA 
são de responsabilidade de uma só professora e restritas a uma só matéria curricular - Ciências; situação essa com a qual a maioria das professoras, contraditoriamente, também concorda. Tal fato ocorre mesmo tendo as demais professoras afirmado sua competência para ensinar EA, inclusive discordando da complexidade relacionada a aspectos como planejamento e implementação das atividades de ensino. 8) Em relação ao planejamento das atividades de EA, outra aparente contradição se impõe: enquanto a maioria das professoras afirma que, em suas escolas, esta é uma atividade em que há participação de todo o corpo docente, somente uma delas, responsável pelas atividades de EA admitiu ser esse, realmente, o procedimento habitual em sua escola. Esse fato, por si só, indica a impossibilidade, caso seja mantida essa postura, de um trabalho interdisciplinar. 9) Mesmo reconhecendo a necessidade e a importância da vivência, pelos alunos, de atividades múltiplas em locais variados e com recursos diversos (incluindo-se entre esses pessoas e recursos da comunidade), de modo a permitir a análise da realidade onde vivem, inclusive afirmando ser esse o procedimento normal em suas escolas, a maioria das professoras de Ciências admite ter limitado as atividades de ensino à sala de aula, numa postura tradicional e conservadora - de certa forma, porém, abrandada pela busca da participação mais efetiva dos alunos em atividades como debates, elaboração de textos e pesquisas bibliográficas. As metodologias de ensino utilizadas estão, dessa forma, em desacordo com as opiniões e sugestões dos pais dos alunos e pessoas da comunidade, à medida em que esses enfatizam a necessidade e a importância de os alunos saírem da sala de aula e da escola, na busca do conhecimento. 9) Considerando-se que a maioria das professoras incumbidas de desenvolver atividades de EA estão exercendo sua profissão há pouco tempo (em torno de cinco anos), pôde-se concluir que os cursos de Habilitação ao Magistério estão formando profissionais a partir de uma pedagogia para o passado e não para o futuro. Isso significa, segundo Sureda e Colom (1989, p. 55), que tais cursos aparentemente não possuem a sensibilidade pedagógica de formar os futuros profissionais de maneira apropriada às situações socioculturais e econômicas para as quais nos encaminhamos no século XXI. 10) As professoras envolvidas reconhecem os problemas ambientais existentes no bairro onde moram e possuem conhecimentos teóricos a esse respeito, mas, aparentemente, isso não era suficiente para mobilizá-las e impulsioná-las em direção a uma ação efetiva, fato esse plenamente comprovado pela observação de seus comportamentos na escola e fora dela. 11) As escolas mantêm poucas relações com a comunidade; não ocorrem trocas no sentido do aperfeiçoamento da instituição, ajuda mútua (recursos, informação), busca de soluções para os problemas etc. 


\section{Identificação da situação desejável}

Com base na literatura a respeito da EA no âmbito escolar, foi possível estabelecer os pressupostos que devem orientar a sua implementação de forma a garantir o alcance de suas metas e objetivos, a partir dos princípios orientadores estabelecidos. Tais pressupostos, oriundos da Pedagogia ambiental, ciência que analisa, investiga e teoriza a respeito da EA (CARIDE, 1991, p. 71), orientam como essa deve integrar o currículo de forma a Ambientalizá-lo, isto é, ajustá-lo de forma coerente com os seus princípios conceituais e metodológicos (Novo, 1995, p. 207).

Dentre os pressupostos, destacamos o enfoque interdisciplinar em um modelo multidisciplinar conhecido como Método de infusão (Fig.1), especialmente recomendado pelos especialistas em Pedagogia Ambiental, para o ensino da EA nas séries iniciais do ensino fundamental.

Ressaltam-se, ainda, as metas estabelecidas por Hungerford e Peyton (1985, p. 15-19), a partir da Declaração de Tbilisi - Meta 1: Fundamentos ecológicos - busca fornecer aos alunos os conhecimentos ecológicos suficientes para permitir-lhes tomar decisões ecologicamente seguras no que se refere às questões ambientais; Meta II: Problemas e valores - busca desenvolver nos alunos a sensibilidade ambiental e o reconhecimento de como as ações individuais e coletivas podem influir na relação entre qualidade de vida e qualidade do ambiente e, ainda, gerar problemas ambientais que devem ser resolvidos via investigação, avaliação, clarificação de valores, tomada de decisões e ação

FIGURA 1 - ENFOQUE INTERDISCIPLINAR EM UM MODELO MULTIDISCIPLINAR

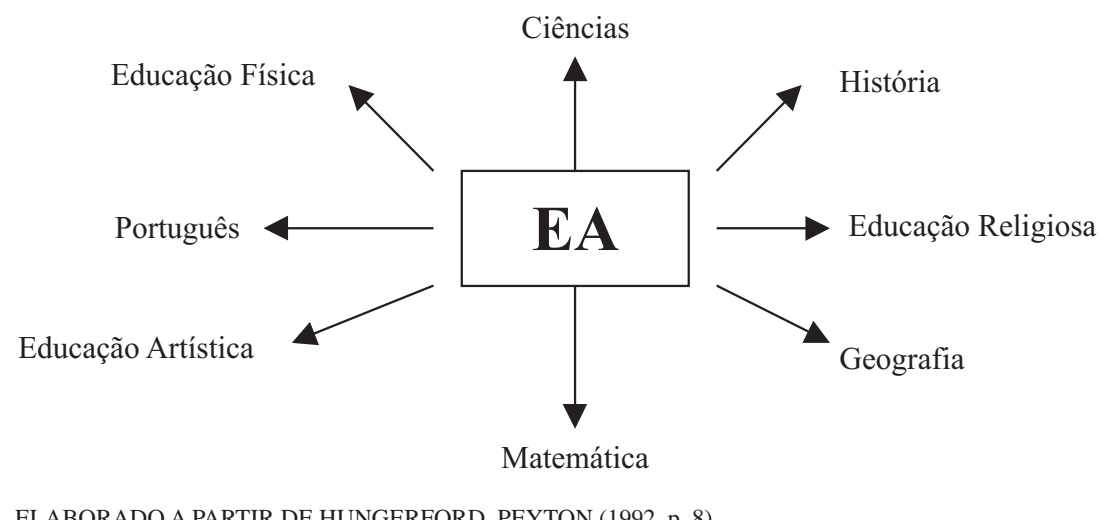


de cidadania. A formação de crenças positivas, valores e atitudes, em relação ao meio ambiente, constitui a base de um comportamento ético responsável e é, portanto, de extrema importância em um projeto de EA. Os valores citados pelos estudiosos como essenciais são: respeito, cidadania, justiça, prudência, tolerância, honestidade, liberdade, paz e generosidade. Meta III: Investigação e avaliação - refere-se à aquisição, pelo aluno, do conhecimento e das habilidades necessárias à investigação de problemas ambientais, proposição e avaliação de soluções alternativas para resolvê-los; Meta IV: Treinamento e aplicação - busca desenvolver nos alunos as habilidades que lhes permitirão efetivamente atuar de acordo com seus valores, tanto individualmente quanto em grupo (persuasão, defesa do consumidor, ação política etc.), bem como tomar decisões a respeito de estratégias de ação para a busca de soluções de problemas ambientais específicos.

\section{Fase de tomada de decisões}

Considerando-se a análise dos dados obtidos com o desenvolvimento das ações previstas nas duas primeiras fases do ANISE e o problema estabelecido, optou-se pela implementação, em caráter experimental, de um projeto de intervenção socioeducativa na Escola Clementina Cruz, localizada no município de Pinhais-PR. As conclusões estabelecidas na fase de diagnóstico evidenciaram a necessidade da realização de curso de atualização para as docentes que participariam do projeto. Assim, com o intuito de obter dados mais precisos a respeito das expectativas apresentadas pelas professoras em relação ao projeto e do seu conhecimento acerca do ensino da EA, dados esses essenciais ao planejamento e avaliação do curso, foi aplicado às docentes um questionário contendo 22 questões, formuladas como perguntas abertas. O conteúdo das questões foi selecionado com base nas habilidades e conhecimentos necessários à incorporação efetiva da dimensão ambiental aos programas escolares sugeridos por Wilke et al. (1994) e Atreya et al. (1995) e nos pressupostos teóricos que embasam o ensino da EA. O mesmo questionário foi aplicado como pós-teste, ao término das atividades experimentais na escola, uma vez que serviu, também, como instrumento para a verificação da eficiência e da eficácia do curso de atualização e das atividades desenvolvidas durante a implementação do projeto. 
A análise das respostas foi realizada de acordo com a metodologia sugerida por Bardin (1979). Fatores como as características do trabalho docente desenvolvido na escola e o tempo disponível para estudo determinaram a escolha da metodologia utilizada no curso - ensino individualizado e do recurso de ensino - módulos instrucionais. Foram elaborados quatro módulos com os seguintes conteúdos: EA: breve retrospectiva histórica; EA: enfoque ético; EA: fundamentos ecológicos e EA: enfoque metodológico. Nesta fase decidiu-se, também, pela aplicação, aos alunos, de um questionário, utilizado como pré e pós-teste, com questões abertas e fechadas, divididas em duas partes: a) gravura representando situações passíveis de serem encontradas na escola, dentro e fora da sala de aula; doze questões visando a avaliar sua capacidade de observação e descrição, de discriminação de valores, atitudes e comportamentos desejáveis e indesejáveis dentro e fora da sala de aula, sua disposição para se envolverem e agirem com o objetivo de modificar as situações indesejáveis tornando a escola um local mais aprazível; e sua percepção a respeito do papel da professora, como educadora; b) gravuras representando uma horta e um parque, com situações envolvendo comportamentos desejáveis e indesejáveis de cidadãos adultos e crianças; vinte e duas questões cujo objetivo era avaliar o entendimento dos alunos a respeito de processos e conceitos ecológicos, sua percepção no que se refere a valores, atitudes e comportamentos dos indivíduos em relação a animais e ao comportamento dos cidadãos na comunidade e sua disposição para agir em prol da proteção do meio ambiente.

\section{O projeto de intervenção socioeducativa}

Como primeira etapa da implementação do projeto de intervenção, buscaram-se estabelecer, com as professoras, os pressupostos teóricos e as diretrizes que o orientariam: conceito de EA; objetivos da EA; metas do ensino da EA; conceito de desenvolvimento sustentável e de meio ambiente; modalidade de interdisciplinaridade; valores a serem desenvolvidos; paradigma educativo (constituído pela justaposição dos modelos cognitivo e ecológico-contextual); projeto de EA do município; objetivos do ensino fundamental; propostas ambientais 
BARRA, V. M. Exploração de necessidades socioeducativas...

do município; os resultados obtidos no processo de análise de necessidades e a proposta curricular da rede municipal de ensino. O projeto foi implementado durante os meses de agosto a dezembro de 1997, com o seguinte objetivo: ao final das atividades previstas, os alunos deveriam apresentar conhecimento, valores, atitudes e comportamentos favoráveis à conservação e melhoria do ambiente, que os capacitassem à resolução de problemas ambientais, tomada de decisões e ação nessa perspectiva.

\section{Conclusões}

A relação entre as análises efetuadas no transcurso da pesquisa, as hipóteses e objetivos estabelecidos a partir do problema proposto, possibilitou o estabelecimento de conclusões que são apresentadas, aqui, de modo sucinto: 1 - a EA foi efetivamente incorporada como tema transversal no currículo escolar, tendo seu ensino ocorrido em um enfoque interdisciplinar. O projeto de intervenção, em acordo com o princípio que estabelece que a verdadeira integração só é concretizada quando se consegue ambientalizar o currículo, permitiu que os conteúdos desenvolvidos aproximassem os alunos do seu entorno, possibilitando-lhes uma análise crítica da realidade e o desenvolvimento de destrezas para sua melhoria, a partir de um enfoque ambientalmente correto. Esse resultado deveu-se ao fato de que, em todas as disciplinas, além da aquisição e formação de conceitos, buscou-se, simultaneamente, o desenvolvimento de valores, atitude, destrezas e comportamentos próprios da EA, concretizando as duas situações - $\mathbf{o}$ aprender a aprender e $\mathbf{o}$ aprender a viver (LUCINI, 1995, p. 32). 2 - Como coadjuvante do processo educativo, as atividades vivenciadas tornaram as famílias dos alunos, a escola, o bairro e o município, cenário da EA, com o objetivo de recuperar o ambiente como contexto, como agente de desenvolvimento e como estrutura de condições e recursos. Foram desenvolvidas, ao longo de várias semanas, na escola e na comunidade, inúmeras atividades e todas as disciplinas, que de um ou de outro modo, contribuíram para os resultados alcançados, numa demonstração de um real trabalho interdisciplinar, realizado a partir de um modelo multidisciplinar; vale ressaltar, verdadeiramente interdisciplinar, de vez que superou uma mera integração de aspectos parciais de diferentes áreas do conhecimento ao propiciar uma mudança de atitudes dos alunos no que se refere à compreensão 
dos conteúdos e à importância da sua participação nas atividades pedagógicas; tal participação foi traduzida pelo envolvimento em discussões a respeito de problemas ambientais detectados e, acima de tudo, na vivência de ações com vistas à solução dos mesmos problemas. Essas ações permitiram o alcance do que Paulo Freire (1971; 1974; 1979), denominou de conscientização: um processo de transformação do modo de pensar que implica uma ação a partir da reflexão e que se realiza na relação dialética homem-mundo. 3-As professoras envolvidas no projeto, que mesmo antes da sua implementação reconheciam suas características inovadoras, ao seu término foram unânimes em reafirmar tal posição, agora ancoradas não só nos conhecimentos adquiridos, mas, sobretudo, nos resultados evidenciados ao longo da sua implementação. Creditaram ao projeto, graças à ambientalização curricular promovida, não só a possibilidade de aquisição de novos conhecimentos mas, principalmente, a possibilidade da participação efetiva dos alunos nas atividades propostas. As metodologias adotadas no desenvolvimento do projeto e os conteúdos estudados, ainda de acordo com as professoras, despertaram o interesse dos alunos particularmente por possibilitarem sua participação além daquela usualmente ocorrida ao longo da sua permanência na escola e pela discussão de problemas ambientais que afetam sua vida cotidiana. A sensibilização para com o ambiente, a identificação e discussão a respeito de problemas ambientais do município, a busca de possíveis soluções e a ação para a concretização das mudanças, efetuada a partir de valores e atitudes eticamente desejáveis, atendeu não só os pressupostos metodológicos de um programa de $\mathrm{EA}$, mas também às expectativas dos pais no que se refere à importância, por eles atribuída, ao trabalho escolar na formação de cidadãos ambientalmente responsáveis. Há que se ressaltar que o projeto, ao buscar atender às expectativas da comunidade, desenvolveu conteúdos selecionados a partir dos interesses dos alunos, das características e necessidades do entorno, numa atitude de desvinculação do livro didático, até então a fonte prioritária dos temas para estudo. As estratégias buscaram, dessa forma, comprometer a escola e os alunos com o desenvolvimento do território, a partir da integração daqueles em projetos educativos, atingindo, satisfatoriamente, na opinião das professoras, as metas estabelecidas por Hungerford e Peyton (1985, p. 15-19), que configuram a situação desejável do ensino da EA. 4 - Seria muita pretensão afirmar que todos os alunos apresentaram as mudanças desejadas seja no que se refere à aquisição de conhecimentos, seja no desenvolvimento de valores, atitudes e habilidades ou, ainda, à adoção de comportamentos ambientalmente responsáveis. No entanto, foi possível o progresso quantitativo e qualitativo no desempenho dos alunos, com maior destaque à questão relativa à cidadania e aos valores a ela associados. Em 
contrapartida, no que se refere ao entendimento de processos ecológicos fundamentais para o desenvolvimento de atividades de EA, os dados obtidos não foram os desejados. Mesmo após a implementação do projeto, os alunos continuaram a demonstrar um conhecimento apenas parcial de determinados processos ecológicos. Uma possível explicação para tal resultado estaria no fato de que as atividades, tanto nas aulas de Ciências como nas das demais disciplinas, não foram suficientes para a aprendizagem esperada. 5 - Em que pese o condicionamento acarretado pelo tipo de formação que receberam em escolas tradicionalistas (que consideram a formação acadêmica do aluno seu objetivo principal - escolas em geral alheias ao ambiente e seus problemas, centradas na sala de aula e focando conhecimentos contidos nos livros didáticos como verdades que não admitem contestações), a análise dos dados obtidos com o instrumento de pré e pós teste e aqueles coletados no curso da implementação do projeto, demonstrou que as professoras se empenharam no sentido de superar suas limitações e aquelas oriundas do sistema de ensino vigente no município. No entanto, mesmo após a implementação do projeto, cujo objetivo primordial foi o desenvolvimento de valores ambientais, as professoras continuaram a priorizar, em seus planos de ensino, a inclusão de assuntos relativos aos problemas ambientais do município, ainda que numa abordagem preservacionista-conservacionista. A mudança qualitativa, porém, é evidenciada pelas justificativas apresentadas para tal escolha: não mais o simples reconhecimento de fatos mas, acima de tudo, a preocupação com as conseqüências destes na qualidade de vida das pessoas. Este fato torna-se claro quando se verificam os objetivos pretendidos, frutos dessa nova abordagem: participação, conscientização, adoção de comportamentos ambientalmente corretos e busca de soluções para os problemas.

As conclusões alcançadas permitem inferir que os objetivos da pesquisa foram alcançados. Há que se ressaltar a obtenção de resultados adicionais não diretamente relacionados aos objetivos da pesquisa, como, por exemplo, a mudança de atitudes de funcionárias da escola no que se refere à sua interação com os alunos (evidenciada por comportamentos menos opressores) e ao seu papel no sistema escolar (evidenciada pela participação espontânea nas atividades educativas). No entanto, cabe lembrar, como afirma Sobrado (1995, p. 13), que não há um programa perfeito quando levado a cabo pela primeira vez.

\section{REFERÊNCIAS}


ATREYA, B. D. et al. Educación ambiental: programa de formación continua para maestros e inspectores de ensenãnza primaria. Bilbao: Los libros de la Catarata, 1995.

BARDIN, L. Análise de conteúdo. Lisboa: Edições 70, 1970.

CARIDE, J. A. La educación ambiental: concepto,historia y perspectivas. In: CARIDE, J. A. et al. (Orgs.). Educación ambiental: realidades e perspectivas. Santiago de Compostela: Torculo, 1991. p. 7-86,

FREIRE, P. Conscientização. São Paulo: Cortez e Moraes, 1979.

HUNGERFORD, H.; PEYTON, R. Procedures for Developing an Environmental Education Curriculum. Paris:Unesco, 1990.

KELLNER, R. Environmental Concern Inventory. Form k4. Wisconsin: Project ICE, 1971.

LUCINI, F. Temas transversales y áreas curriculares. Madrid: Anaya, 1995.

NOVO, M. La educación ambiental. Bases éticas, conceptuales y metodologicas. Madrid: Editorial Universitas, 1995.

PATTON, M. H. Qualitive Evaluation Methods. Sage: Newbury Park, 1989.

PÉREZ-CAMPANERO, M. P. Como detectar las necessidades de intervención socioeducativa. Madrid: Narcea, 1991.

PILLAR, A, D. Desenho e escrita como sistemas de representação. Porto Alegre: Artes Médicas, 1996.

SOBRADO, L, F. Evaluación de programas de orientación psicopedagógica. Caesura, Canoas, v. 7. p. 67-82, 1995.

SUREDA, J.; COLOM, A. Pedagogia ambiental. Barcelona: CEAC, 1989.

WILKE, R. et al. Estratégias para la formación del professorado en educacion ambiental. Bilbao: Los Libros de la Catarata, 1994.

ZABALZA, M. A. El ambiente desde una perspectiva curricular. In: CARIDE, J. A. et al. (Orgs.). Educacion ambiental: realidades y perspectivas. Santiago de Compostela: Torculo, 1991. p. 243-297.

Texto recebido em 06 nov. 2005 Texto aprovado em 19 dez.2005 